\title{
Pemetaan Kluster Perumahan di Kecamatan Biringkanaya dan Tamalanrea Kota Makassar dengan Quantum GIS
}

\author{
Vita Fajriani Ridwan ${ }^{1, a}$ dan Haeril Adi Hasanuddin ${ }^{1, b}$ \\ ${ }^{1}$ Jurusan Teknik Sipil, Politeknik Negeri Ujungpandang, J1. Perintis Kemerdekaan KM. 10 Tamalanrea Makassar 90245 \\ avitaridwan@gmail.com \\ bhaeril.abdi@poliupg.ac.id
}

Abstract-Biringkanaya and Tamalanrea sub-districts are Makassar's eastern suburbs that experience urban sprawl. Regional sprawl (urban sprawl) which occurs one of them is indicated due to uncontrolled housing cluster growth. The phenomenon of urban sprawl has an impact on city morphology, transportation systems, environment and energy. This study aims to analyze the distribution pattern and density level of housing clusters in Biringkanaya and Tamalanrea sub-districts through mapping housing clusters in the region. This research method is carried out by survey for primary data collection in the form of housing cluster and area using Garmin $76 \mathrm{CSX}$ which will be combined with Quickbird imagery maps using Quantum GIS, then digitizing buildings from GPS data overlay and image maps. The results of this study are clear spatial data in the form of a digital map based on geographic information about the position and density of residential clusters in Biringkaya Subdistrict and Tamalanrea District, Makassar City. From the results of this analysis found housing cluster patterns in these two sub-districts scattered following the Independence Pioneering arterial path with a spawling pattern, besides that it also uses a domino pattern and fills between one housing and another. Also Biringkanaya Subdistrict is the most populous sub-district of its housing cluster compared to Kecamatan Tamalanrea.

Keywords-Biringkanaya Dstrict; Tamalanrea District; City of Makassar; urban sprawl; Quantum GIS

\footnotetext{
Abstrak-Kecamatan Biringkanaya dan Tamalanrea merupakan kawasan suburban timur Makassar yang mengalami urban sprawl. Pelebaraan wilayah (urban sprawl) yang terjadi salah satunya diindikasikan akibat pertumbuhan kluster perumahan yang tidak terkendali. Fenomena urban sprawl berdampak pada morfologi kota, sistem transportasi, lingkungan hingga energi. Penelitian ini bertujuan untuk menganalisis pola persebaran dan tingkat kepadatan kluster perumahan di Kecamatan Biringkanaya dan Tamalanrea melalui pemetaan kluster perumahan di kawasan ini. Metode penelitian ini dilakukan dengan cara survey untuk pengambilan data primer berupa posisi dan luas kluster perumahan menggunakan alat bantu GPS Garmin 76 CSX yang akan digabungkan dengan peta citra Quickbird dengan menggunakan Quantum GIS, kemudian dilakukan digitasi bangunan dari overlay data GPS dan peta
}

citra. Hasil dari penelitian ini adalah data spasial yang jelas berupa peta digital berbasis informasi geografi tentang posisi dan kepadatan kluster perumahan di Kecamatan Biringkaya dan Kecamatan Tamalanrea Kota Makassar. Dari hasil analisis ini ditemukan pola kluster perumahan di kedua kecamatan ini tersebar mengikuti Jalur arteri Perintis Kemerdekaan dengan pola spawling, selain itu juga menggunakan pola domino dan saling mengisi antara perumahan yang satu dan yang lain. Juga Kecamatan Biringkanaya adalah kecamatan yang terpadat kluster perumahannya dibandingan Kecamatan Tamalanrea.

Kata Kunci-Kecamatan Biringkanaya, Kecamatan Tamalanrea, Kota Makassar, urban sprawl, Quantum GIS

\section{Pendahuluan}

Jumlah penduduk di Kota Makassar adalah 1.352.136 dengan laju pertumbuhan penduduk 1.56 yang tersebar di 14 Kecamatan dan 143 Kelurahan menurut [1]. Terdapat sekitar $29 \%$ pertumbuhan penduduk di area suburban. Di area perkembangan ke arah Timur (Kawasan Tamalenrea, Biringkanaya), 221.224 jiwa dengan pertumbuhan populasi $2,30 \%$, dan di area perkembangan kota ke arah selatan (Kawasan Tamalate), 154.464 jiwa dengan pertumbuhan populasi 2,08\%. Dalam penelitian [2] menyatakan bahwa pertumbuhan populasi di area suburban lebih besar dibandingkan dengan pertumbuhan populasi Makassar $(1.63 \%)$.

Dalam persepsi perencanaan prasarana, pertumbuhan penduduk berbanding lurus dengan penyedian infrastruktur mulai dari transportasi hingga pemukiman. Pertumbuhan penduduk membuat Makassar mengalami fase morfologi, dimana Makassar bertumbuh secara melebar hingga ke suburban. Kawasan suburban berkembang menjadi kantongkantong pemukiman yang semrawut. Kasus wilayah suburban Kota Makassar, terdapat kurang lebih 133 kluster perumahan, tumbuh tidak terkendali, kepadatan rendah, pada jarak berbeda-beda dari urban (kota inti), menyebar mengikuti +20 $\mathrm{km}$ panjang jalan poros urban-suburban Makassar dan jalan regional Sulawesi Selatan menurut [2]. Senada dengan [3] yang menggambarkan kluster perumahan yang tumbuh 
sporadis di sepanjang Jalan Perintis Kemerdekaan yang merupakan kawasan suburban Makassar bagian timur. Fenomena ini kini dikenal sebagai urban sprawl yang ditandai oleh adanya alih fungsi lahan yang ada di sekitar kota (urban periphery) yang tidak terkontrol.

Menurut penelitian [2], terjadi inefisiensi penggunaan lahan dan infrastruktur di kawasan suburban Timur Makassar akibat urban sprawl yang ditandai dengan perkebangan kluster perumahan yang tidak terkendali, senada dengan kesimpulan [3] tentang tingginya pergerakan di kawasan suburban timur Makassar akibat urban sprawl, sementara menurut [4], ratarata urban sprawl di Kecamatan Biringkanya cukup besar

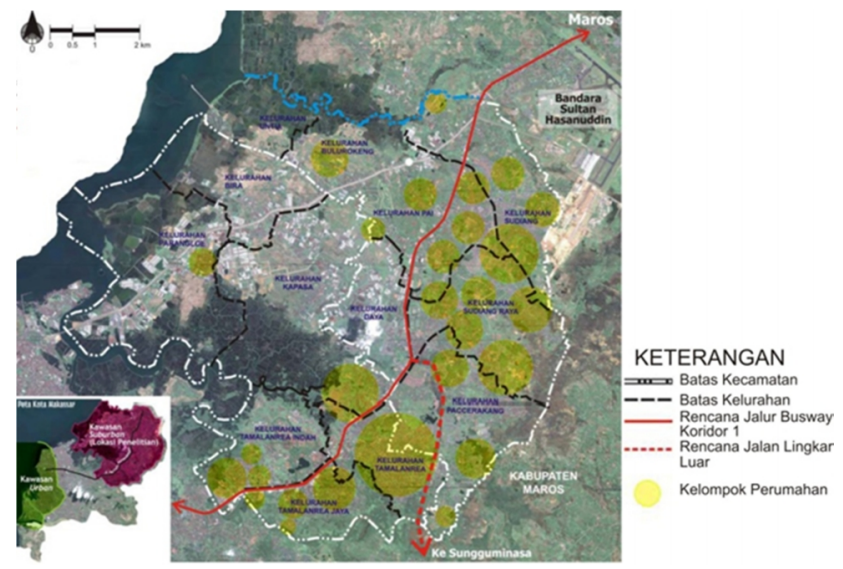

Gambar 1. Kluster perumahan di suburban Timur Makassar [3]

Berdasarkan permasalahan perkembangan spasial kota dan transportasi di kawasan suburban timur Makassar (Kecamatan Biringkanaya dan Tamalanrea) di atas, maka menurut peneliti harus dilakuakan analisis pola persebaran kluster perumahan di kawasan ini. Analisis ini dapat dilakukan dengan identifikasi spasial melalui pemetaan kluster perumahan di kawasan ini dengan menggunakan aplikasi berbasis SIG (QGIS). Penelitian sebelumnya yang dilakukan [3], hanya melakukan capture perkiraan posisi kluster perumahan di kedua kecamatan tersebut (Gambar 1), tanpa data berupa sistem informasi, seperti jumlah rumah dan populasi pada kluster perumahan tersebut, sehingga tidak dapat digunakan untuk mengetahui jumlah tarikan dan bangkitan pada lokasi tersebut. Dengan mengetahui tarikan dan bangkitan pada satu lokasi, maka perencanaan sistem transportasi pada lokasi tersebut dapat dibuat lebih maksimal.

Quantum GIS (QGIS) adalah aplikasi SIG gratis yang mencakup pemetaan, analisis spasial, dan beberapa fitur DesktopGIS lainnya. Aplikasi ini samadengan paket aplikasi GIS komersial namun aplikasi ini didistribusikan secara gratis dibawah lisensi GNU dan multi-platform yang dapat dijalankan pada sistem operasi yang berbeda-beda termasuk MacOS X, Linux, Unix dan Windows. QGIS juga memiliki kemampuan untuk bekerjasama dengan paket aplikasi komersil terkait. QGIS menyediakan semua fungsionalitas dan fitur-fitur yang dibutuhkan oleh pengguna GIS pada umumnya. Menggunakan plugins dan fitur inti (core features) dimungkinkan untuk menvisualisasi (meragakan) pemetaan (maps) untuk kemudian diedit dan dicetak sebagai sebuah peta yang lengkap. Pengguna dapat menggabungkan data yang dimiliki untuk dianalisa, diedit dan dikelola sesuai dengan apayang diinginkan. QuantumGIS juga mendukung format data vektor, raster, dan database (PostGIS dan Oracle). QuantumGIS juga dapat diprogram ulang untuk mengerjakan tugas yang berbeda atau lebih spesifik

\section{Metode Penelitian}

Penelitian ini dilakukan selama delapan bulan mulai dari bulan Januari sampai bulan Agustus 2016 dengan lokasi penelitian di Kecamatan Biringkanaya dan Tamalanrea, Kota Makassar Propinsi Sulawesi Selatan.

Data sekunder yang dibutuhkan pada penelitian ini adalah Data Citra satelit Quickbird (0,61 m) Kecamatan Biringkanaya dan Tamalanrea Kota Makassar 2014, data kluster perumahan di Kecamatan Biringkanaya dan Tamalanrea tahun 2014yang disajikan oleh [3], dan peta digital jaringan Jalan Perintis Kemerdekaan tahun 2014. Instrumen yang digunakan dalam penelitian ini, adalah Global Positioning System (GPS) navigasi, Kendaraan roda empat, Komputer PC atau Laptop sebagai pengolah data, perangkat lunak MapSource, Google Earth, AutoCAD 2010, dan printer.

\subsection{Prosedur Penelitian}

\section{A. Teknik Pengumpulan Data}

Teknik survey, Teknik ini untuk pengambilan data primer, yaitu posisi dan luas kluster perumahan menggunakan alat bantu GPS Garmin 76 CSX. Data ini diolah bersama peta citra digital Kecamatan Biringkanaya dan Tamalanrea Kota Makassar

Citra digital, Teknik ini untuk pengambilan data peta citra digital Quickbird Kecamatan Biringkanaya dan Tamalanrea Kota Makassar 2014 dengan tingkat resolusi $0.61 \mathrm{M}$ menggunakan google earth.

\section{B. Prosedur Penelitian}

Prosedur penelitian adalah sistematika atau urutan kegiatan pada penelitian ini. Adapun prosedur penelitian ini adalah sebagai berikut:

1. Melakukan survey lokasi

2. Pengumpulan data berupa pengambilan koordinat lokasi perumahan dan melakukan tracking luas perumahan dengan GPS (data spasial)

3. Pengambilan peta citra digital Kecamatan Biringkanaya dan Tamalanrea Kota Makassar dengan google earth

4. Ploting data dari GPS ke QGIS

5. Digitasi bangunan di kluster perumahan untuk mengetahui tingkat kepadatan perumahan dengan QGIS

6. Overlay data dengan QGIS

7. Pembuatan peta kluster perumahan di Kecamatan Biringkanaya dan Tamalanrea Kota Makassar

8. Analisis pola persebaran kluster perumahan di Kecamatan Biringkanaya dan Tamalanrea Kota Makassar 
9. Menghitung tingkat kepadatan kluster perumahan di Kecamatan Biringkanaya dan Tamalanrea Kota Makassar dengan QGIS.

\section{Hasil dan Pembahasan}

Penelitian ini dilakukan dengan pendekatan deskriptif kuantitatif dengan metode pemetaan kluster perumahan dengan Quantum GIS. Metode ini kami lakukan dengan menggunakan metode overlay yang merupakan metode analisis keruangan melalui proses tumpang susun atau overlay antara dua atau lebih layer tematik untuk mendapatkan tematik kombinasi baru sesuai dengan persamaan yang dipergunakan. Pada penelitian ini kami mencoba selain mempolakan kluster perumahan di kedua kecamatan (Biringkanaya dan Tamalanrea), juga berusaha melakukan analisis dengan melakukan overlay terhadap jalan dan kecamatan itu sendiri.

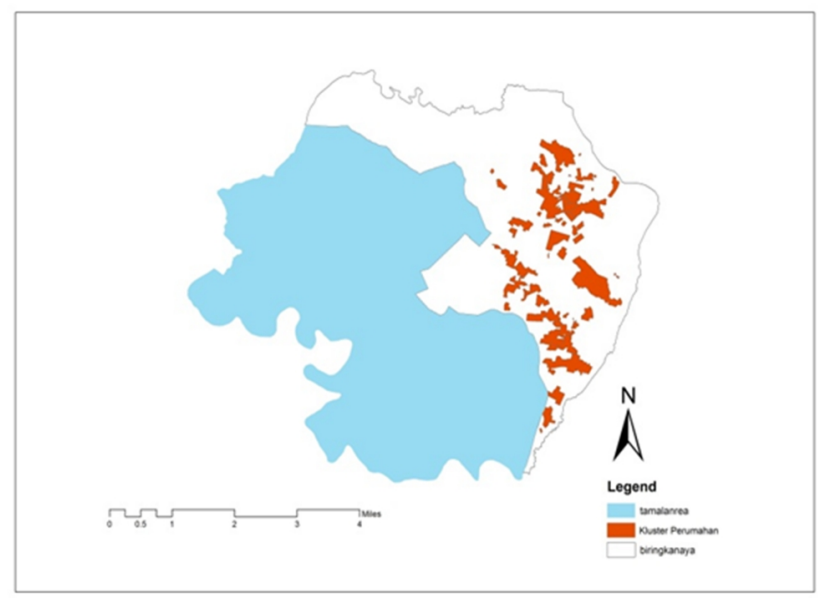

Gambar 2. Sebaran kluster di Kecamatan Biringkanaya

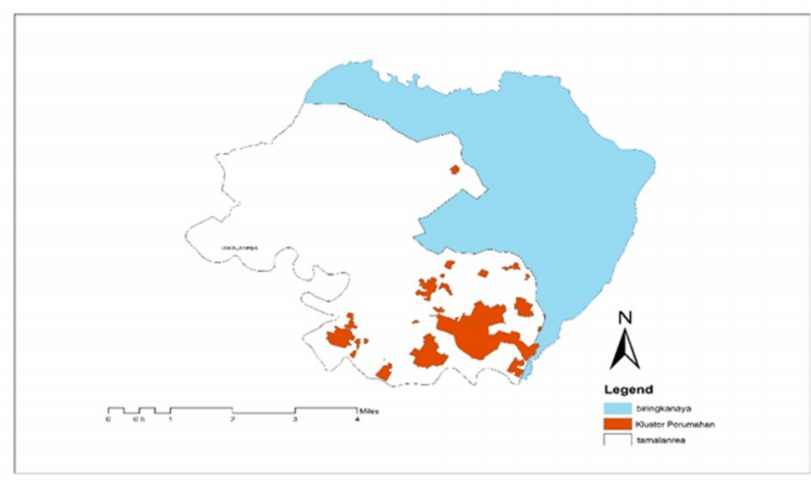

Gambar 3. Sebaran kluster di Kecamatan Biringkanaya

Pada Gambar 2 terlihat terlihat peta persebaran kluster perumahan yang dioverlay dengan peta jalan. Dari gambar ini memperlihatkan sebuah pola persebaran secara sprawling mengikuti Jalan Perintis Kemerdekaan bahkan beberapa kluster perumahan terkoneksi langsung dengan Jalan Perintis Kemerdekaan. Kluster perumahan ini sebagai kawasan tinggal penduduk, menjadi sumber tarikan dan bangkitan pergerakan penduduk yang berafiliasi pada pergerakan transportasi, dan pergerakan transportasi ini akan mengalami penumpukan karena sebagian besar kluster perumahan yang terkoneksi dengan Jalan Perintis Kemerdekaan bukan terkategori jalan kolektor, tetapi jalan lokal, sehingga perpecahan dan akses kendaraan yang masuk menjadi kacau dan tidak terstruktur. Selain konsep sprawling yang terbentuk pada kluster perumahan di dua kecamatan ini, juga terbentuk sebuah pola domino diantara perumahan, dimana diantara perumahan saling menempel satu sama lain bahkan banyak yang saling mengisi antara perumahan yang satu dengan yang lain.

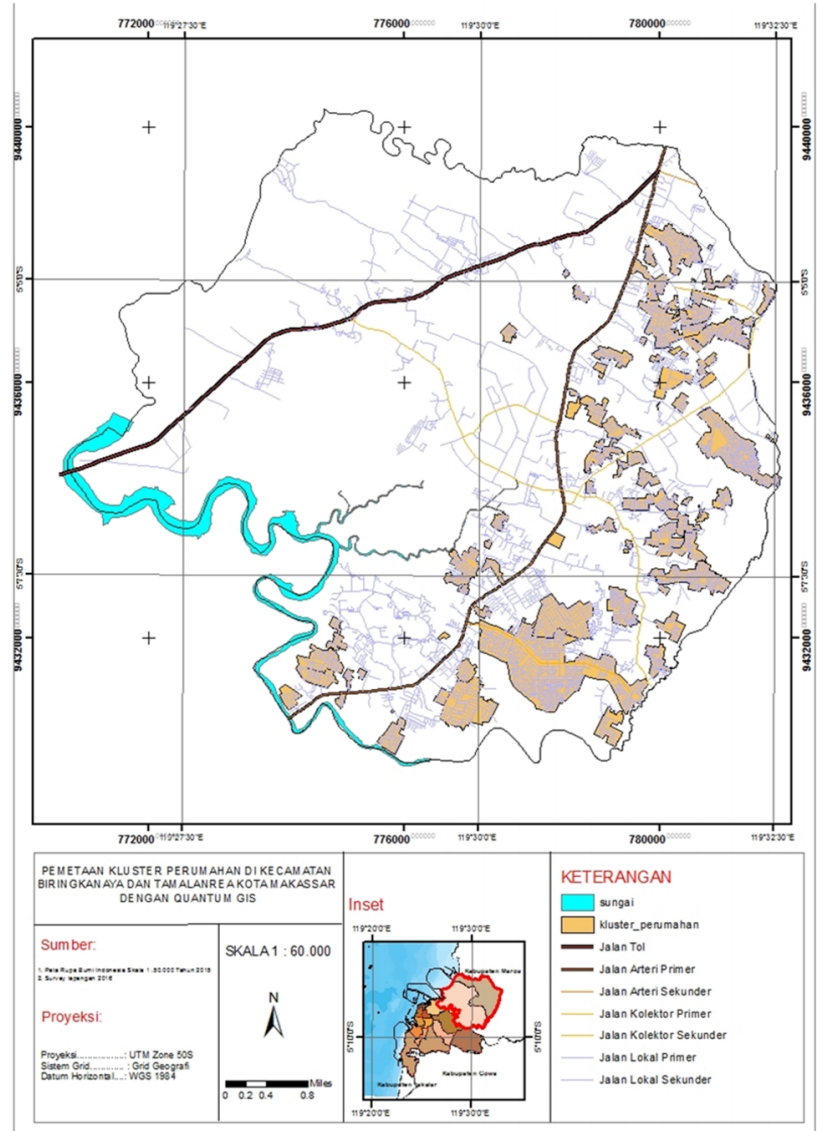

Gambar 4. Sebaran Kluster Perumahan

Sedangkan pada gambar 3 terlihat peta kluster perumahan yang ditumpangtindihkan dengan peta kecamatan memperlihatkan sebuah pola pengembangan kawasan sub urban (Kecamatan Biringkanaya) yang lebih padat dibandingkan dengan kecamatan Tamalanrea. Hal ini juga didukung setelah dilakukan analisis spasial dengan plugin clip di Quantum GIS, diketahui total luas perumahan di Kecamatan Biringkanaya adalah $6.414 .791 .750 \quad \mathrm{M} 2$, sedangkan di Kecamatan Tamalanrea adalah 4.274.613.6070 M2 (lihat lampiran 1). Fenomena pertumbuhan perumahan di kawaan sub urban utara Kota Makassar ini dikenal sebagai fenomena urban sprawl. 


\section{Kesimpulan}

Berdasarkan hasil penelitian yang telah dilakukan maka dapat diambil beberapa kesimpulan yaitu:

1. Pola persebaran klustere perumahan di kedua kecamatan ini memanjang mengikuti jalan arteri primer Perintis Kemerdekaan, selain itu juga menggunakan pola domino dan saling mengisi antara perumahan yang satu dan yang lain.

2. Kecamatan Biringkanaya adalah kecamatan yang terpadat kluster perumahannya dibandingan Kecamatan Tamalanrea.

\section{Ucapan Terima Kasih}

Ucapan terima kasih diberikan kepada badan yang banyak memberikan kontribusi positif bagi penyelesaian penelitian ini termasuk didalamnya sponsor yang membiayai penelitian ini.

\section{Daftar Pustaka}

[1] BPS Kota Makassar. 2013. Kota Makassar dalam Angka

[2] Wunas, S. 2011. Kota Humanis, Integrasi Guna Lahan dan Transportasi di Wilayah Suburban. Brilian Internasional. Surabaya

[3] Veronika, N dan Wunas. S. 2011. Integrated Spatial Planning And Transportation System to Reduce Mobility in Suburban Area. In the 14 FSTPT International Symposium. Pekanbaru.

[4] Wero, Sri Wahyuni, 2012. Perambahan Kota (Urban Sprawl) terhadap Lahan Pertanian di Kota Makassar Berdasarkan Citra Satelit Landsat 5 TM (Studi Kasus Kecamatan Biringkanaya). Fakultas Pertanian. Universitas Hasanuddin. Makassar 